\title{
TDAG51 deficiency promotes oxidative stress-induced apoptosis through the generation of reactive oxygen species in mouse embryonic fibroblasts
}

\author{
Eui-Soon Park ${ }^{1}$, Juhyeok Kim ${ }^{1}$, Tae-uk Ha ${ }^{1}$, Jong-Soon Choi ${ }^{2,3}$, Kwan Soo Hong ${ }^{3,4}$ and Jaerang Rho ${ }^{1,3}$ \\ Apoptosis has an important role in maintaining tissue homeostasis in cellular stress responses such as inflammation, \\ endoplasmic reticulum stress, and oxidative stress. T-cell death-associated gene 51 (TDAG51) is a member of the pleckstrin \\ homology-like domain family and was first identified as a pro-apoptotic gene in T-cell receptor-mediated cell death. However, \\ its pro-apoptotic function remains controversial. In this study, we investigated the role of TDAG51 in oxidative stress-induced \\ apoptotic cell death in mouse embryonic fibroblasts (MEFs). TDAG51 expression was highly increased by oxidative stress \\ responses. In response to oxidative stress, the production of intracellular reactive oxygen species was significantly enhanced in \\ TDAG51-deficient MEFs, resulting in the activation of caspase-3. Thus, TDAG51 deficiency promotes apoptotic cell death in \\ MEFs, and these results indicate that TDAG51 has a protective role in oxidative stress-induced cell death in MEFs. \\ Experimental \& Molecular Medicine (2013) 45, e35; doi:10.1038/emm.2013.67; published online 9 August 2013
}

Keywords: apoptosis; oxidative stress; ROS; TDAG51

\section{INTRODUCTION}

Apoptosis has an essential role in tissue homeostasis in various organisms and is activated by a number of cellular stress responses such as oxidative stress, endoplasmic reticulum (ER) stress, and inflammatory responses. ${ }^{1-4}$ The receptor-mediated (extrinsic) and mitochondria-mediated (intrinsic) pathways are two major distinct apoptotic pathways that are active in mammalian cells. ${ }^{5}$ The receptor-mediated pathway is triggered by the stimulation of death receptors such as Fas/CD95 and the tumor necrosis factor receptor superfamily. Ligand interactions with cognate receptors initiate caspase- 8 and methodically activate caspase- 3 . Activated caspase-3 directly induces apoptotic cell death. ${ }^{6}$ The mitochondria-mediated pathway is activated by several cellular stresses, including oxidative stress, ER stress, and growth factor depletion. Cellular stress induces release of cytochrome $c$ from mitochondria, and the released cytochrome $\mathrm{c}$ binds to apoptotic protease activating factor-1 and caspase-9. This complex directly induces caspase- 3 activation and subsequently activates apoptotic cell death. ${ }^{7,8}$
Reactive oxygen species (ROS) are generated during mitochondrial oxidative metabolism, as well as during cellular responses to xenobiotics, cytokines, and bacterial invasion. ${ }^{9}$ The generation and accumulation of intracellular ROS can lead to intrinsic oxidative stress in cells. ${ }^{4}$ ROS are noxious to cells; therefore, the cell has defense mechanisms to eliminate intracellular ROS accumulation. However, an imbalance between ROS generation and elimination induces severe cellular oxidative stress. Excessive ROS derived from endogenous or exogenous routes can damage or cause complete degradation of essential molecules, including cellular lipids, proteins, and DNA, resulting in activation-induced apoptotic cell death (AICD). ${ }^{4,10}$ Therefore, the modulation of the oxidative stress response in cells is closely related to a series of human diseases such as neurodegeneration, atherosclerosis, diabetes, aging, and even cancer. ${ }^{9}$

T-cell death-associated gene 51 (TDAG51) was first described to have roles in the induction of CD95/Fas gene expression and AICD in response to the engagement of the T-cell receptor in a murine T-cell hybridoma. ${ }^{11}$ This gene is

\footnotetext{
${ }^{1}$ Department of Microbiology and Molecular Biology, College of Bioscience and Biotechnology, Chungnam National University, Daejeon, Korea; ${ }^{2}$ Division of Life Science, Korea Basic Science Institute, Daejeon, Korea; ${ }^{3}$ Graduate School of Analytical Science and Technology, Chungnam National University, Daejeon, Korea and ${ }^{4}$ Division of MR Research, Korea Basic Science Institute, Daejeon, Korea

Correspondence: Professor J Rho, Department of Microbiology and Molecular Biology, Chungnam National University, College of Bioscience and Biotechnology, 220 Gung-dong, Yuseong-gu, Daejeon 305 764, Republic of Korea.

E-mail: jrrho@cnu.ac.kr
}

Received 7 December 2012; revised 30 May 2013; accepted 11 June 2013 
also known as pleckstrin homology-like domain family A member 1 (PHLDA1), and it possesses an N-terminal pleckstrin homology-like domain. ${ }^{12}$ In the C-terminal region, TDAG51 contains both a proline-glutamine (PQ) repeat domain and a proline-histidine $(\mathrm{PH})$ repeat domain, which may be involved in its pro-apoptotic function. ${ }^{11,13,14}$ However, we have previously shown that TDAG51 is not required for AICD in murine $\mathrm{T}$ cells in an in vivo study using TDAG51deficient (TDAG51 ${ }^{-/-}$) mice. ${ }^{15}$ A human T-cell study further confirmed that TDAG51 expression is not correlated with AICD in human $\mathrm{T}$ cells. ${ }^{16}$ Collectively, the precise role of TDAG51 in apoptotic cell death remains controversial; therefore, it is important to elucidate whether TDAG51 expression is involved in pro-apoptotic or anti-apoptotic functions.

In the present study, we investigated the role of TDAG51 in oxidative stress-induced apoptosis in TDAG51 $1^{-1-}$ mouse embryonic fibroblasts (MEFs). We observed that TDAG51 expression is significantly induced by oxidative stress in MEFs. Upon oxidative stress, TDAG51 deficiency results in enhanced generation of ROS in TDAG51 ${ }^{-1-}$ MEFs. Thus, TDAG51 ${ }^{-/-}$ MEFs were more sensitive to oxidative stress-induced apoptosis compared to wild-type (TDAG51 ${ }^{+/+}$) MEFs. These results suggest that TDAG51 deficiency promotes oxidative stressinduced apoptosis in MEFs.

\section{MATERIALS AND METHODS}

\section{Chemicals, antibodies, and mice}

Hydrogen peroxide $\left(\mathrm{H}_{2} \mathrm{O}_{2}\right)$, 4',6-diamidino-2-phenylindol (DAPI), propidium iodide (PI), and $2^{\prime}, 7^{\prime}$-dichlorofluorescein diacetate (DCFH-DA) were purchased from Sigma-Aldrich (St Louis, MO, USA). The following signaling inhibitors were purchased: SP600125 (c-Jun N-terminal kinase (JNK), Santa Cruz Biotechnology, Santa Cruz, CA, USA), PD98059 (extracellular signal-regulated kinase (ERK), Cell Signaling, Beverly, MA, USA), SB203580 (p38, Santa

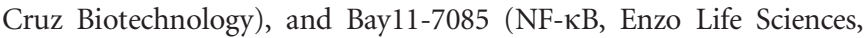
Farmingdale, NY, USA). The TDAG51 antibody was purchased from Santa Cruz Biotechnology. Specific antibodies against caspase-3, caspase-9, and Bax were purchased from Cell Signaling Technology. The $\beta$-actin antibody was purchased from Sigma-Aldrich. TDAG51 ${ }^{-}$ - mice were generated as previously described. ${ }^{15}$ All animal studies were approved (approval No. 10/02/09) by the Animal Experiment Ethics Committee of Chungnam National University.

\section{MEF isolation and culture}

Embryos generated from the intercross of TDAG51 heterozygous knockout (TDAG51 $1^{+/-}$) mice were dissected out of decidua, and all maternal tissues were removed. MEFs were isolated from each mouse embryo at embryonic day (E) 13.5. The brain and visceral organs of E13.5 embryos were surgically removed, and the remainder of the embryonic body was finely minced with sterile animal operating scissors. The minced embryos were treated repeatedly with $0.05 \%$ trypsin at $37^{\circ} \mathrm{C}$ for $10 \mathrm{~min}$ with intermittent agitation to isolate MEFs. MEFs were maintained in Dulbecco's modified Eagle's medium (Welgene, Daegu, Korea) supplemented with 15\% fetal bovine serum (Invitrogen, Carlsbad, CA, USA), $1 \mathrm{~mm}$ L-glutamine (Welgene), and $1 \times$ antibiotic/antimycotic solution (Welgene) in $5 \% \mathrm{CO}_{2}$ at $37^{\circ} \mathrm{C}$. The average yield from an embryo was $\sim 3 \times 10^{7}$ cells. To determine
MEF genotypes, genomic DNA was extracted from MEFs, and the cells were genotyped by PCR as described previously. ${ }^{15}$

\section{Immunoblotting assay}

Total cell lysates were prepared using ice-cold lysis buffer $(25 \mathrm{~mm}$ Tris$\mathrm{HCl}$ ( $\mathrm{pH}$ 7.5), $150 \mathrm{~mm} \mathrm{NaCl}, 1 \mathrm{~mm}$ EDTA, $1 \mathrm{~mm} \mathrm{NaF}, 1 \mathrm{~mm}$ sodium orthovanadate, $1 \mathrm{~mm}$ phenylmethylsulfonyl fluoride, 5\% glycerol, and $0.5 \%$ Triton X-100). Lysates were separated by $10 \%$ SDS-PAGE and transferred to a polyvinylidene difluoride membrane (Amersham Biosciences, Piscataway, NJ, USA). The membrane was probed with specific antibodies, and immunoreactivity was detected using enhanced chemiluminescent reagents (Amersham Biosciences). For signaling inhibition, MEFs were treated with SP600125 (JNK, $20 \mu \mathrm{M}$ ), PD98059 (ERK, $20 \mu \mathrm{M})$, SB203580 (p38, $20 \mu \mathrm{M})$, and Bay11-7085 (NF$\kappa \mathrm{B}, 1 \mu \mathrm{M}$ ) with $0.5 \mathrm{~mm} \mathrm{H}_{2} \mathrm{O}_{2}$ for $1 \mathrm{~h}$, and the cell lysates were analyzed by immunoblotting as described above.

\section{Apoptotic cell death assays}

Isolated MEFs were seeded in 6-well plates $\left(2 \times 10^{5}\right.$ cells ml $\left.^{-1}\right)$ and further cultured for $24 \mathrm{~h}$. To induce apoptotic cell death, MEFs were then treated with the indicated concentration of $\mathrm{H}_{2} \mathrm{O}_{2}$ for $6 \mathrm{~h}$. Cell survival was determined using DAPI staining and PI staining as previously described. ${ }^{17,18}$ For DAPI staining, the cells were washed twice with ice-cold $1 \times$ phosphate-buffered saline (Welgene), fixed with $4 \%$ paraformaldehyde for $10 \mathrm{~min}$, and then stained with $0.1 \mu \mathrm{g} \mathrm{ml}^{-1}$ of DAPI (Sigma-Aldrich). Finally, the cells were observed under an inverted fluorescence microscope (DM-IRB, Leica Microsystems, Wetzlar, Germany). For PI staining, the dead cells were stained with $1 \mu \mathrm{g} \mathrm{ml}^{-1}$ of PI for $1 \mathrm{~min}$ at room temperature and analyzed using a flow cytometer (FACSCalibur, BectonDickinson, San Jose, CA, USA).

\section{Determination of generated ROS}

Intracellular ROS were measured with a flow cytometer using DCFHDA (Sigma-Aldrich) as previously described. ${ }^{19}$ Briefly, MEFs $\left(2 \times 10^{5}\right.$ cells $\mathrm{ml}^{-1}$ ) were cultured in 6-well plates. After $24 \mathrm{~h}, \mathrm{MEF}$ were incubated in serum-free culture medium without phenol red, and the cells were stimulated with $0.5 \mathrm{~mm} \mathrm{H}_{2} \mathrm{O}_{2}$ in a time-dependent manner. After $\mathrm{H}_{2} \mathrm{O}_{2}$ stimulation, the cells were washed twice with phosphatebuffered saline and then incubated with $10 \mu \mathrm{M}$ DCFH-DA for $30 \mathrm{~min}$. Finally, the cells were harvested using cell dissociation solution (Sigma-Aldrich) and resuspended in phosphate-buffered saline containing 2\% fetal bovine serum. Quantification of ROS was measured by flow cytometry using the FACSCalibur.

\section{Construction of RNA interference expression vector and retroviral infection}

TDAG51 RNA interference (TDAG51i) oligonucleotides (sense, 5'-GA T CCC CGT CTA CCA GGC AGA AGC ATT CAA GAG ATG CTT CTG CCT GGT AGA CTT TTT A-3'; antisense, 5'-AGC TTA AAA AGT CTA CCA GGC AGA AGC ATC TCT TGA ATG CTT CTG CCT GGT AGA CGG G-3') were synthesized and cloned into the pSuperretro-puro (OligoEngine, Seattle, WA, USA) retroviral vector (pSRTDAG51i). Green fluorescent protein (GFP) RNA interference (GFPi) was used as a control as described previously. ${ }^{20}$ Retroviral soups harboring TDAG51 $i$ or GFP $i$ were prepared as described previously. ${ }^{20}$ Briefly, Plat.E (retrovirus packaging cell line) cells were cultured on a $60 \mathrm{~mm}$ dish $\left(2 \times 10^{6}\right.$ cells per dish $)$. pSR-TDAG51i $(5 \mu \mathrm{g})$ or GFP $i$ $(5 \mu \mathrm{g})$ was transfected into Plat.E cells using TurboFect transfection reagent (Fermentas, Glen Burnie, MD, USA) according to the 
manufacturer's instructions. At $24 \mathrm{~h}$ post transfection, retroviral soups harboring TDAG51 $i$ or GFP $i$ were collected and were used to infect MEFs $\left(1.5 \times 10^{6}\right.$ cells per $60-\mathrm{mm}$ dish $)$ with $8 \mu \mathrm{g} \mathrm{ml}^{-1}$ polybrene (Sigma-Aldrich) for $6 \mathrm{~h}$. At $6 \mathrm{~h}$ post infection, MEFs were selected with $2 \mu \mathrm{g} \mathrm{ml}^{-1}$ puromycin (Sigma-Aldrich) for 2 days. Puromycinresistant MEFs were used for further experiments.

\section{Luciferase reporter assays}

The murine TDAG51 promoter $\left(\mathrm{P}_{\mathrm{T} 51}-3 \mathrm{~K}\right.$-Luc) from -2450 to +551 was amplified by PCR and cloned into the pGL3-basic vector (Promega, Madison, WI, USA). A luciferase reporter assay was performed as described previously. ${ }^{21}$ Briefly, MEFs were plated on 24-well plates $\left(0.5 \times 10^{5}\right.$ cells per well), and the cells were cotransfected with the TDAG51 promoter plasmid and $\beta$-galactosidase expression plasmid. All transfections were performed in triplicate using TurboFect transfection reagent (Fermentas) following the manufacturer's instructions. At $48 \mathrm{~h}$ post transfection, MEFs were treated with $0.5 \mathrm{mM} \mathrm{H}_{2} \mathrm{O}_{2}$ for $1 \mathrm{~h}$ in the presence or absence of the signaling inhibitors described above. The cells were evaluated for luciferase activity using a luciferase assay kit (Promega). All values represent luciferase activity normalized to $\beta$-galactosidase activity.

\section{Statistical analysis}

All experiments were performed at least three times. Data represent the mean \pm s.d. ( $n=3$ per group). Student's $t$-test was used to determine the significance of differences between experimental samples.

\section{RESULTS}

The expression of TDAG51 is enhanced by oxidative stress TDAG51 is a known cellular stress-responsive gene; ${ }^{11,13,14}$ therefore, we first examined whether TDAG51 expression is enhanced by oxidative stresses in a time- and concentrationdependent manner. First, TDAG51 ${ }^{+/+}$MEFs were stimulated for $8 \mathrm{~h}$ with $\mathrm{H}_{2} \mathrm{O}_{2}$ in a dose-dependent manner. As a result, TDAG51 gene expression was greatly enhanced by $\mathrm{H}_{2} \mathrm{O}_{2}$ treatment in the concentration range between $0.5-0.8 \mathrm{~mm}$ (Figure 1a). Accordingly, the next study was designed to determine the relationship between time-dependent expression of TDAG51 and oxidative stresses. To determine TDAG51 expression during oxidative stress, TDAG51 ${ }^{+/+}$MEFs were stimulated with $0.5 \mathrm{mM} \mathrm{H}_{2} \mathrm{O}_{2}$ in a time-dependent manner. We observed that TDAG51 expression was significantly enhanced by $\mathrm{H}_{2} \mathrm{O}_{2}$ stimulation, and the cells were found to exhibit peak TDAG51 expression after $8 \mathrm{~h}$ of $\mathrm{H}_{2} \mathrm{O}_{2}$ stimulation (Figure 1b). Similarly, we detected elevated TDAG51 expression by $\mathrm{H}_{2} \mathrm{O}_{2}$ stimulation in other cell types such as Huh-7, 293T, and HeLa cells (Figure 1b). However, concordant with the results of previous reports, ${ }^{13,14}$ TDAG51 induction showed cell type-dependent differential expression; a rapid increase in TDAG51 expression was observed in 293T cells with a peak at $2 \mathrm{~h}$, whereas a gradual increase in TDAG51 expression reached a peak at $12 \mathrm{~h}$ in Huh-7 and HeLa cells (Figure 1b). To further confirm the effect of oxidative stress on TDAG51 expression, we used $250 \mathrm{~mm}$ ethanol as another oxidative stressor to treat TDAG51 $+1+$ MEFs in a time-dependent manner. Similar results were obtained demonstrating that TDAG51 expression was significantly elevated by ethanol treatment, although the

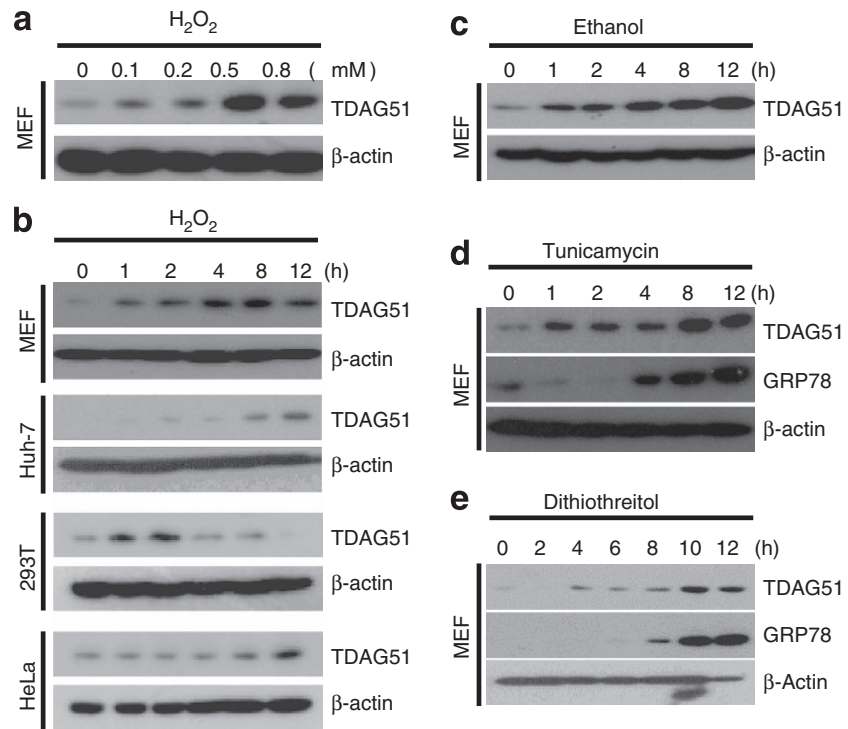

Figure 1 The expression of T-cell death-associated gene 51 (TDAG51) is enhanced by oxidative stress. (a) TDAG51 expression induced by $\mathrm{H}_{2} \mathrm{O}_{2}$ stimulation in mouse embryonic fibroblasts (MEFs). TDAG51+1+ MEFs were stimulated for $8 \mathrm{~h}$ with the indicated concentration of hydrogen peroxide $\left(\mathrm{H}_{2} \mathrm{O}_{2}\right)$. TDAG51 was detected by western blot analysis with anti-TDAG51 antibody. $\beta$ Actin was used as a loading control. (b) TDAG51 expression induced by $\mathrm{H}_{2} \mathrm{O}_{2}$ stimulation in various cells. Cells were stimulated with $0.5 \mathrm{~mm} \mathrm{H}_{2} \mathrm{O}_{2}$ for the indicated time periods. (c) TDAG51 expression induced by $0.25 \mathrm{~m}$ ethanol treatment in MEFs. (d) TDAG51 expression induced by tunicamycin $\left(1 \mu \mathrm{g} \mathrm{ml}{ }^{-1}\right)$ treatment in MEFs. (e) TDAG51 expression induced by $5 \mathrm{~mm}$ dithiothreitol treatment in MEFs.

peak expression of TDAG51 was slightly delayed (Figure 1c). ER stress induced by the unfolded protein response is closely linked to the generation and accumulation of intracellular ROS, which can lead to intrinsic oxidative stress in cells. ${ }^{4}$ Thus, we next examined whether TDAG51 expression is enhanced by ER stress responses. Upon treatment with ER stressors such as tunicamycin and dithiothreitol, we observed that the increased expression of TDAG51 appeared to correlate with the expression of the major ER stress marker GRP78 (Figures 1d and e). These results suggest that TDAG51 is an oxidative stress-responsive gene product.

To further examine the mechanism of TDAG51 induction by oxidative stress, we generated TDAG51 promoter-reporter constructs harboring a $3 \mathrm{~kb}$ murine TDAG51 promoter fragment driving expression of the luciferase gene (Figure 2a). In the luciferase assays, we observed that the activity of the TDAG51 $3 \mathrm{~kb}$ promoter ( $\left.\mathrm{P}_{\mathrm{T} 51}-3 \mathrm{~K}-\mathrm{Luc}\right)$ was induced in a dosedependent manner by $\mathrm{H}_{2} \mathrm{O}_{2}$ stimulation (Figure $2 \mathrm{a}$ ). We next determined whether mitogen-activated protein kinases and NF- $\kappa$ B signaling are involved in TDAG51 induction by $\mathrm{H}_{2} \mathrm{O}_{2}$ stimulation. The promoter activities of $\mathrm{P}_{\mathrm{T} 51}-3 \mathrm{~K}-\mathrm{Luc}$ were reduced by treatment with inhibitors of mitogen-activated protein kinases and NF- $\kappa \mathrm{B}$ signaling (Figure $2 \mathrm{~b}$ ). Coincidently, we observed that the induction of TDAG51 protein was 
a

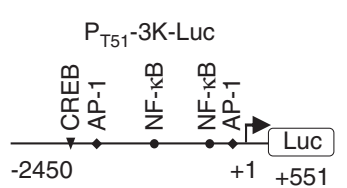

C

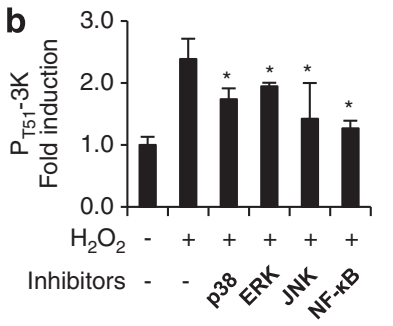

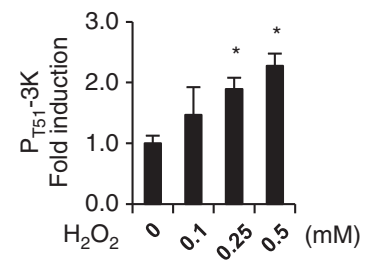

a

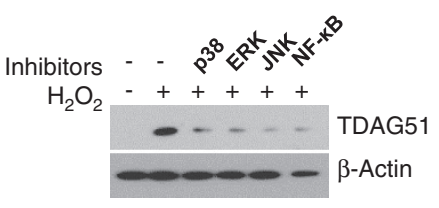

Figure 2 Gene expression of T-cell death-associated gene 51 (TDAG51) is mediated by oxidative stress-induced mitogenactivated protein (MAP) kinases and NF- $\kappa B$ signaling in mouse embryonic fibroblasts (MEFs). (a) The effect of hydrogen peroxide $\left(\mathrm{H}_{2} \mathrm{O}_{2}\right)$ stimulation on the transcriptional activity of the TDAG51 promoter. Schematic diagram of TDAG51 promoter ( $\mathrm{P}_{\mathrm{T} 51}-3 \mathrm{~K}-\mathrm{LuC}$ ) was shown in the left panel. The nucleotide positions were numbered based on transcriptional start site, and the putative binding site of transcription factor was marked on the line. CREB, CAMP response element-binding protein; AP-1, activator protein-1. The luciferase activity of the TDAG51 promoter ( $\left.P_{T 51}-3 K-L u c\right)$ was measured by $\mathrm{H}_{2} \mathrm{O}_{2}$ stimulation for $1 \mathrm{~h}$ (right). ${ }^{*} P<0.05$. (b) The effect of inhibitors of MAP kinases and NF- $\mathrm{KB}$ signaling on the transcriptional activity of the TDAG51 promoter. $\mathrm{P}_{\mathrm{T} 51-3 \mathrm{~K}-\text { Luc- }}$ transfected MEFs were treated with inhibitors and subsequently stimulated by $\mathrm{H}_{2} \mathrm{O}_{2}$ treatment $(0.5 \mathrm{~mm})$. ${ }^{*} P<0.05$. (c) The effect of inhibitors of MAP kinases and NF- $\mathrm{KB}$ signaling on TDAG51 induction during $\mathrm{H}_{2} \mathrm{O}_{2}$ stimulation. MEFs were treated with inhibitors and subsequently stimulated by $\mathrm{H}_{2} \mathrm{O}_{2}$ treatment $(0.5 \mathrm{~mm})$. TDAG51 induction was analyzed by western blot analysis. $\beta$-actin was used as a loading control.

significantly reduced by treatment with inhibitors of mitogenactivated protein kinases and NF- $\kappa \mathrm{B}$ signaling (Figure $2 \mathrm{c}$ ). These results indicate that TDAG51 expression is modulated by mitogen-activated protein kinases and NF- $\kappa \mathrm{B}$ signaling in response to $\mathrm{H}_{2} \mathrm{O}_{2}$ stimulation.

TDAG51 deficiency enhances intracellular ROS generation Intracellular ROS production is dramatically increased in cellular responses to environmental stimuli.9,22 TDAG51 expression is involved in the oxidative stress response as shown in Figure 1; therefore, we examined whether TDAG51 deficiency affects the level of intracellular ROS production. To evaluate the effects of intracellular ROS production caused by TDAG51 deficiency, TDAG51-l- MEFs were treated with $0.5 \mathrm{mM} \mathrm{H}_{2} \mathrm{O}_{2}$ for several time points, incubated with DCFH$\mathrm{DA}$, and then analyzed by flow cytometry. As shown in Figure 3a, intracellular ROS production in TDAG51 ${ }^{-/-}$MEFs was significantly enhanced by $\mathrm{H}_{2} \mathrm{O}_{2}$ stimulation compared to TDAG51 $1^{+/+}$MEFs. The level of intracellular ROS production was quantified and summarized in Figure $3 \mathrm{~b}$. Intracellular ROS production was significantly enhanced in a time-
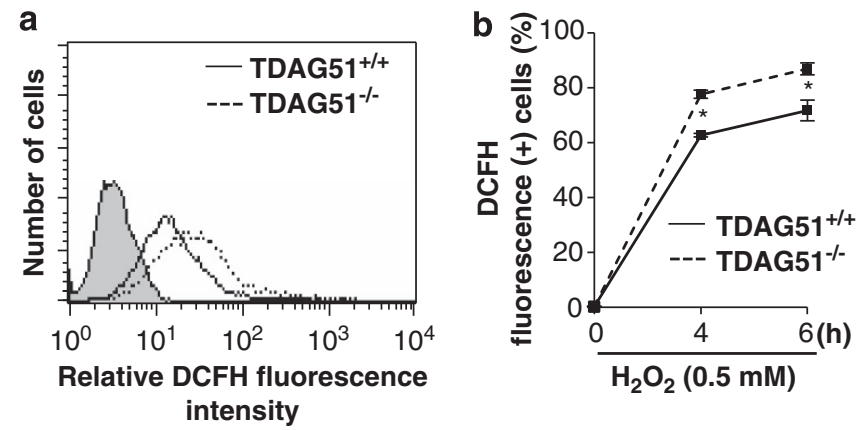

Figure 3 Enhanced intracellular reactive oxygen species (ROS) generation caused by the oxidative stress response in T-cell deathassociated gene 51 deficient (TDAG51 ${ }^{-1-}$ ) mouse embryonic fibroblasts (MEFs). (a) The comparison of intracellular ROS generation between TDAG51-abundant (TDAG51 ${ }^{+/+}$) and TDAG51 ${ }^{-l-}$ MEFs. MEFs were stimulated with $0.5 \mathrm{~mm} \mathrm{H}_{2} \mathrm{O}_{2}$ for $6 \mathrm{~h}$ with $2^{\prime}, 7^{\prime}$-dichlorofluorescein diacetate, and then the relative dichlorofluorescin (DCFH) fluorescence was analyzed by flow cytometry. (b) Summarized results of intracellular ROS production induced by $\mathrm{H}_{2} \mathrm{O}_{2}$ stimulation. All values are the mean \pm s.d. for triplicate cultures. ${ }^{*} P<0.05$.

dependent manner by $\mathrm{H}_{2} \mathrm{O}_{2}$ stimulation in TDAG51 ${ }^{-1-}$ MEFs compared to TDAG51+l+ MEFs (Figure 3b). Taken together, these results indicate that TDAG51 deficiency enhances intracellular ROS production during the oxidative stress response.

\section{Oxidative stress-induced apoptosis is elevated in TDAG51 ${ }^{-/-}$MEFs}

Oxidative stress induces intracellular ROS accumulation in cells, which results in apoptotic cell death. ${ }^{9,22}$ Accordingly, we next compared apoptotic cell death between TDAG51 ${ }^{+/+}$and TDAG51 ${ }^{-/}$MEFs induced by $\mathrm{H}_{2} \mathrm{O}_{2}$ stimulation. To test this comparison, MEFs were treated with $\mathrm{H}_{2} \mathrm{O}_{2}$ for $6 \mathrm{~h}$, and cell survival was determined by DAPI staining. Cell survival was remarkably reduced 1.9 - to 3.6-fold by $\mathrm{H}_{2} \mathrm{O}_{2}$ stimulation in TDAG51 $^{-/-}$MEFs compared to TDAG51 $+/+$MEFs (Figure 4a). These results were reconfirmed by PI staining, which demonstrated that TDAG51-l- MEFs were more sensitive (1.3- to 2.1-fold) to $\mathrm{H}_{2} \mathrm{O}_{2}$-induced cell death compared to TDAG51+I+ MEFs (Figure 4b). Similarly, cell survival decreased in a time-dependent manner after treatment with $0.5 \mathrm{mM} \mathrm{H}_{2} \mathrm{O}_{2}$ in TDAG51 ${ }^{-l}$ MEFs compared to TDAG51 $1^{+/+}$MEFs (Figure 4c). Caspase-3 activation by the apoptosome during the oxidative stress response is a final effector phase that subsequently activates apoptotic cell death. ${ }^{7,8}$ Oxidative stress-induced cell death was significantly enhanced in TDAG51-l- MEFs as shown in Figures $4 \mathrm{a}-\mathrm{c}$; therefore, we next examined whether caspase- 3 activation is enhanced by $\mathrm{H}_{2} \mathrm{O}_{2}$ stimulation in TDAG51-/- MEFs. To test this idea, we treated MEFs with $0.5 \mathrm{mM} \mathrm{H}_{2} \mathrm{O}_{2}$ in a timedependent manner and examined the process of caspase- 3 activation by western blot analysis with a specific antibody against the active form of caspase-3. We observed that the active form of caspase- 3 was significantly increased in 
a

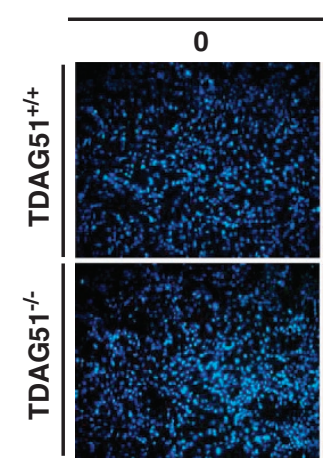

$\mathrm{H}_{2} \mathrm{O}_{2}(\mathrm{mM})$

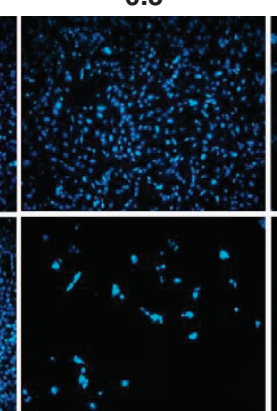

PI staining

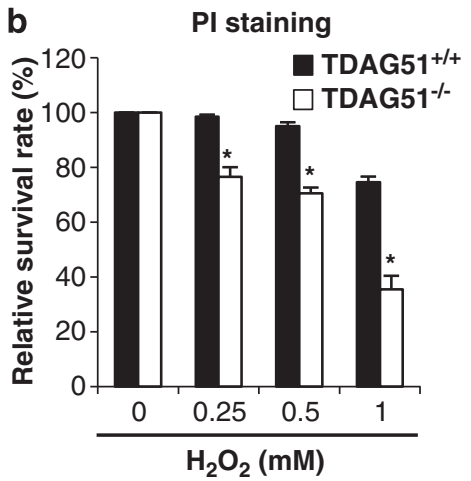

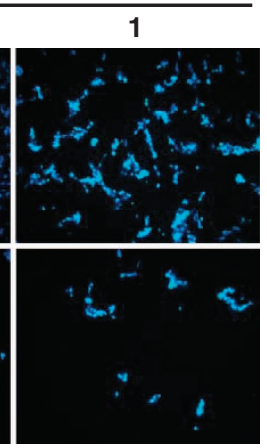

C
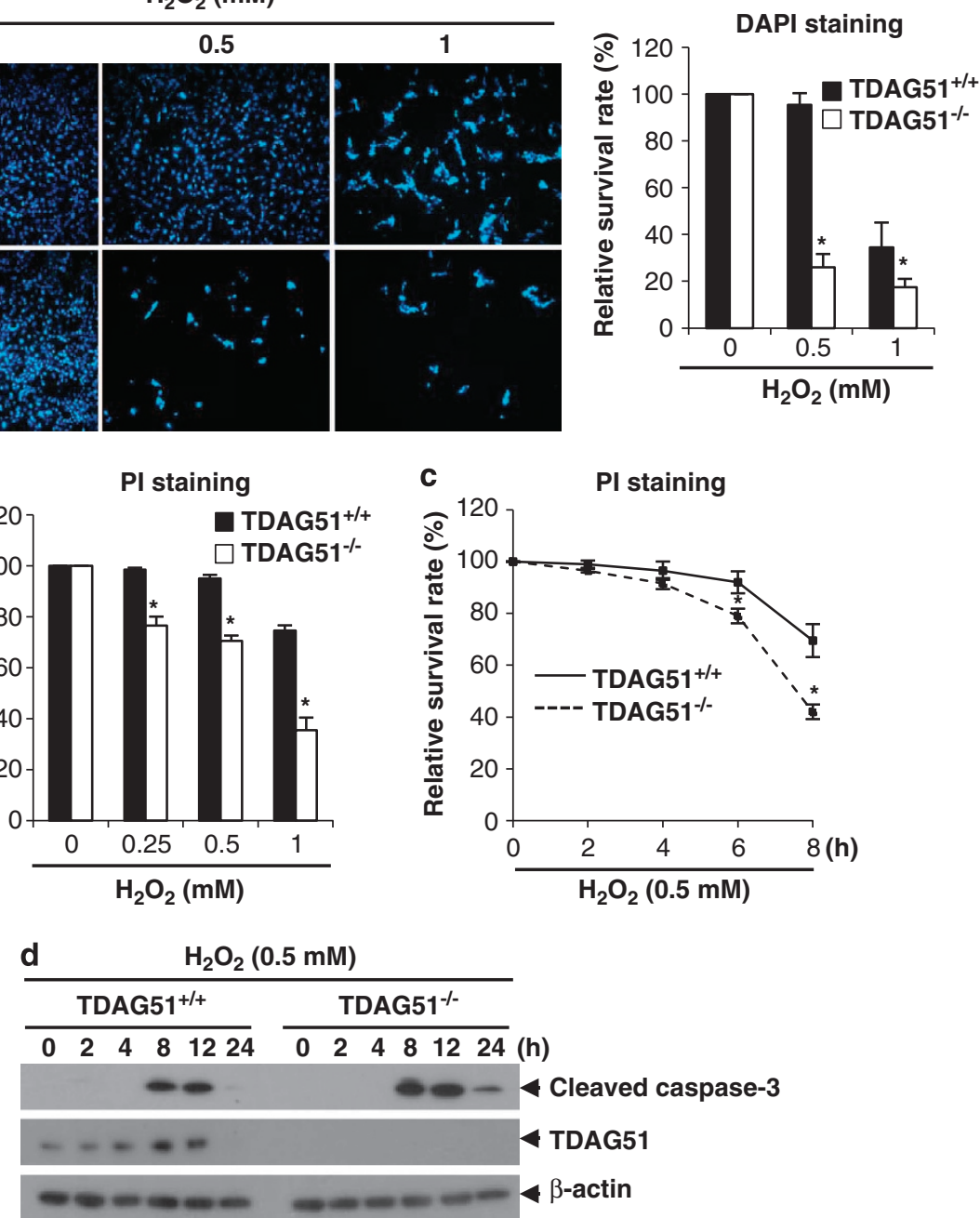

Figure 4 Oxidative stress-induced apoptosis is elevated in T-cell death-associated gene 51 deficient (TDAG51 ${ }^{-/-}$) mouse embryonic fibroblasts (MEFs). (a) Comparison of oxidative stress-induced apoptotic cell death between TDAG51-abundant (TDAG51+/+) and TDAG51 - - MEFs by 4',6-diamidino-2-phenylindol (DAPI) staining. MEFs were cultured with $\mathrm{H}_{2} \mathrm{O}_{2}$ at the indicated concentration for $10 \mathrm{~h}$. The proportion of surviving cells was photographed (left) and determined (right) by DAPI staining. (b) Dose-dependent cytotoxic effects of $\mathrm{H}_{2} \mathrm{O}_{2}$ treatment on TDAG51 $1^{-/}$- MEFs were determined by propidium iodide (PI) staining. MEFs were treated with $\mathrm{H}_{2} \mathrm{O}_{2}$ at the indicated concentrations for $6 \mathrm{~h}$. The proportion of surviving cells was measured by PI staining and flow cytometry. (c) Time-dependent cytotoxic effects of $\mathrm{H}_{2} \mathrm{O}_{2}$ treatment on TDAG51-l- MEFs were determined by PI staining. MEFs were treated with $0.5 \mathrm{~mm} \mathrm{H}_{2} \mathrm{O}_{2}$ for the indicated time points. The proportion of surviving cells was measured by PI staining and flow cytometry. All values are the mean \pm s.d. for triplicate cultures. ${ }^{*} P<0.05$. (d) Caspase-3 activation in TDAG51 ${ }^{-1-} \mathrm{MEFs}$ following $\mathrm{H}_{2} \mathrm{O}_{2}$ stimulation. MEFs were cultured with 0.5 mm $\mathrm{H}_{2} \mathrm{O}_{2}$ in a time-dependent manner. Caspase-3 activation was determined by western blot analysis with a specific antibody against cleaved caspase-3. $\beta$-Actin was used as a loading control.

TDAG51 ${ }^{-I^{-}}$MEFs compared to TDAG51 ${ }^{+/+}$MEFs after $\mathrm{H}_{2} \mathrm{O}_{2}$ stimulation (Figure $4 \mathrm{~d}$ ). These observations indicate that TDAG51 has a protective role in oxidative stress-induced cell death.

To further examine the anti-apoptotic function of TDAG51, we investigated whether knocking down the expression of the endogenous TDAG51 gene via RNA interference (RNA $i$ ) would affect oxidative stress-induced apoptosis in MEFs. We cloned a short hairpin RNA (shRNA) specific for TDAG51 into the pSuper-retro-puro vector (pSR-TDAG51i) and performed western blot analysis to test the effects of the TDAG51 RNA $i$
(TDAG51i). GFP $i$ was used as a control as described previously. ${ }^{20}$ We observed that the expression of TDAG51 was significantly decreased in response to the introduction of TDAG51 $i$ into 293T cells (Figure 5a). Next, retroviral short hairpin RNA-infected MEFs were treated with $\mathrm{H}_{2} \mathrm{O}_{2}$ for $6 \mathrm{~h}$, and cell survival was determined by DAPI staining. Consistent with the results in TDAG51 ${ }^{-1-}$ MEFs (Figure 4), cell survival was reduced 1.5 - to 2.7 -fold by $\mathrm{H}_{2} \mathrm{O}_{2}$ stimulation in TDAG51 $i$ transduced MEFs compared with GFPi-transduced MEFs (Figure 5b). Similarly, we observed that the active form of caspase-3 was significantly increased in TDAG51i-transduced 


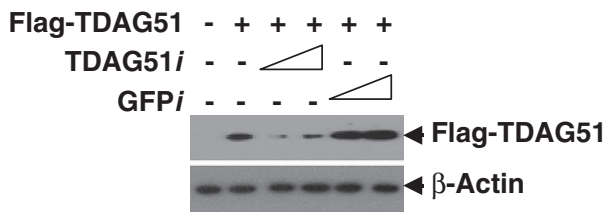

b
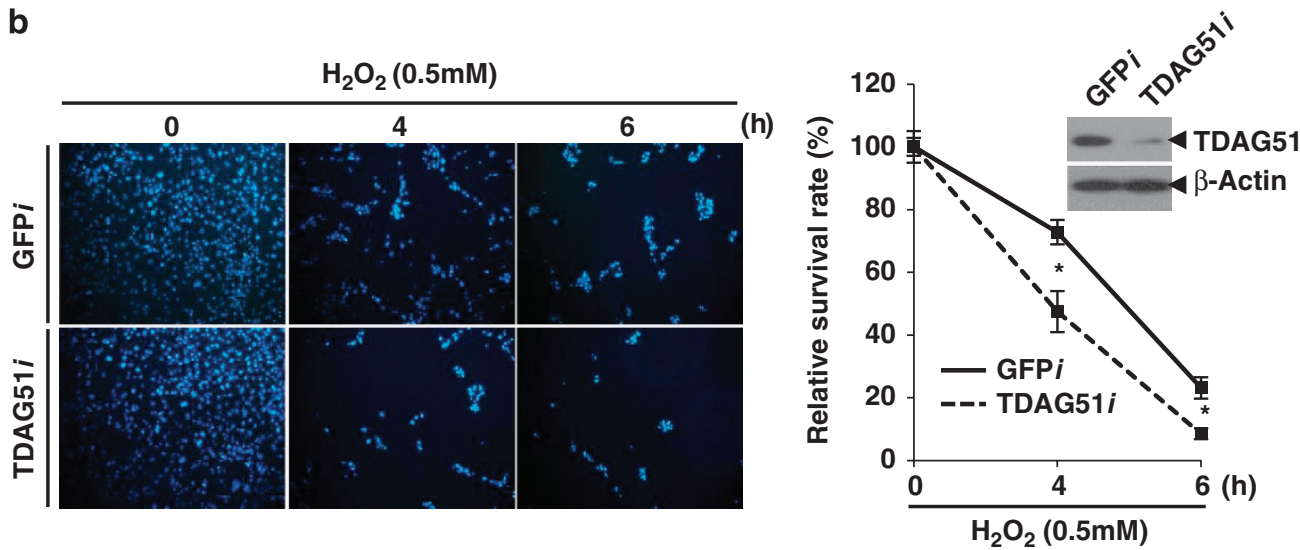

C
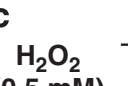

GFP $i$

TDAG51 $i$

(0.5 mM)

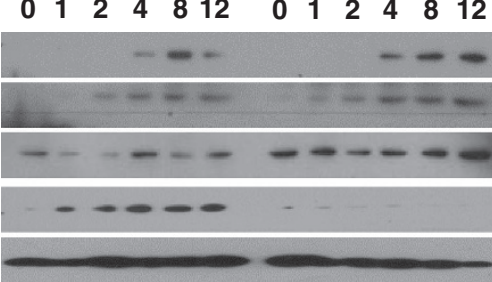

(h)

Cleaved caspase 3

4 Cleaved caspase 9

4 Bax

TDAG51

$\beta$-Actin

Figure 5 Oxidative stress-induced apoptosis is enhanced in T-cell death-associated gene 51 (TDAG51)-knockdown mouse embryonic fibroblasts (MEFs). (a) Analysis of the effects of TDAG51 knockdown by western blot analysis in 293T cells. TDAG51 knockdown was visualized by anti-Flag immunoblotting. Green fluorescent protein (GFP) RNA interference (GFPi) was used as a control. (b) Comparison of oxidative stress-induced apoptotic cell death between TDAG51 knockdown (TDAG51i) and control (GFP $i$ ) MEFs by 4',6-diamidino-2phenylindol (DAPI) staining. MEFs were cultured with $0.5 \mathrm{~mm} \mathrm{H}_{2} \mathrm{O}_{2}$ for $6 \mathrm{~h}$. The proportion of surviving cells was photographed (left) and determined by DAPI staining (right). GFP $i$ was used as a control. TDAG51 knockdown was visualized by anti-TDAG51 immunoblotting (upper right panel). ${ }^{*} P<0.05$. (c) Caspase activation in TDAG51-knockdown MEFs following $\mathrm{H}_{2} \mathrm{O}_{2}$ stimulation. MEFs were cultured with $0.5 \mathrm{~mm} \mathrm{H}_{2} \mathrm{O}_{2}$ in a time-dependent manner. The activation of apoptotic proteins was determined by western blot analysis with specific antibodies against caspase-3, caspase-9, and Bax. $\beta$-Actin was used as a loading control.

MEFs compared with GFP $i$-transduced MEFs after $\mathrm{H}_{2} \mathrm{O}_{2}$ stimulation. Furthermore, we observed that the levels of cleaved caspase-9 and Bax were increased in TDAG51 $i$ transduced $\mathrm{MEF}$ s after $\mathrm{H}_{2} \mathrm{O}_{2}$ stimulation (Figure $5 \mathrm{c}$ ). In summary, we conclude that oxidative stress-induced apoptosis is elevated in TDAG51 $1^{-1-}$ MEFs.

\section{DISCUSSION}

Apoptosis is an elaborate cellular process that removes damaged or infected cells from normal tissue in multicellular organisms. Abnormal control of apoptotic cell death is closely related to the development of several types of human diseases such as inflammation, autoimmunity, diabetes, Alzheimer's, and cancer. Thus, understanding the regulatory process of apoptotic cell death is truly important to prevent disease development and for medical intervention. Based on these aspects, we investigated the functional role of TDAG51 expression in oxidative stress-induced apoptotic cell death.

TDAG51 was first identified as a modulator of T-cell apoptosis through the induction of the expression of the death receptor CD95/Fas. ${ }^{11}$ However, to date, several reports demonstrate that TDAG51 may have both pro- and antiapoptotic functions depending on the cellular context and circumstances. Related to the pro-apoptotic function of TDAG51, several reports support the notion that the expression of TDAG51 is closely associated with enhanced apoptosis. ${ }^{11,23-25}$ Specifically, it has been reported that TDAG51 expression is highly induced by homocysteine and heat shock stress, and it promotes apoptotic cell death. ${ }^{13,14}$ In addition, the process of tumorigenesis is enhanced by the downregulation of TDAG51, which results in the inhibition of tumor cell apoptosis. ${ }^{26-28}$ However, in contrast to its proapoptotic function, TDAG51 has also been shown to have an 
important role in insulin-like growth factor-1-induced cell survival. $^{29}$ Similarly, our group and another group have confirmed that TDAG51 expression is not involved in AICD in human and murine $\mathrm{T}$ cells. ${ }^{15,16}$ In addition, several groups reported that TDAG51 expression is highly enhanced in some tumor types such as pancreatic, colon, and intestinal tumors, indicating that TDAG51 may be involved in tumor cell proliferation but not in apoptotic cell death..$^{16,30-32}$ Collectively, the exact role of TDAG51 expression in apoptotic cell death remains controversial. Thus, a better understanding of the functional role of TDAG51 in cell fate control will provide valuable insight into the regulation of tumor development and cellular stress responses.

ROS are ubiquitous, highly reactive, and short-lived derivatives of oxygen metabolism that serve as critical signaling molecules in cell proliferation and cell death. ${ }^{33}$ ROS are generated during energy metabolism by mitochondria and from metabolic processes elsewhere in the cell that cause damage to cellular macromolecules, including nucleic acids, proteins, and lipids. ${ }^{9}$ Therefore, ROS production is considered to be a major cause of cellular oxidative stress. ${ }^{34}$ An imbalance between ROS generation and elimination induces severe oxidative stress in cells, which results in apoptotic cell death. ${ }^{9}$ In this study, we demonstrated that TDAG51 is a negative modulator of apoptotic cell death induced by oxidative stress through the downregulation of ROS generation. However, an interesting question still remains involving the enhancement of ROS generation in TDAG51 ${ }^{-l-}$ MEFs. Under physiological conditions, cellular protection against oxidative damage by ROS accumulation is provided by both enzymatic (for example, superoxide dismutase and catalase) and non-enzymatic (for example, vitamins $\mathrm{E}$ and $\mathrm{C})$ components. ${ }^{33}$ Interestingly, TDAG51 contains both a PQ-repeat domain and a proline-histidinerepeat domain that function as a putative transcriptional activator. $^{11}$ Thus, TDAG51 may be involved in the modulation of the expression of antioxidant enzymes or non-enzymatic components to eliminate excess ROS generation in response to oxidative stress. In addition, ER stress is a major source of ROS production. ${ }^{35}$ Specifically, numerous clues suggest that ER stress induced by the unfolded protein response is linked to the generation of intracellular ROS, which can lead to the oxidative stress response. ${ }^{4,36}$ In another interesting observation, Hinz et al. ${ }^{37}$ suggest that TDAG51 functions as a negative regulator of protein biosynthesis through an interaction with translation regulatory proteins. In our current study, we also observed that TDAG51 expression was significantly enhanced by treatment with ER stressors such as tunicamycin and dithiothreitol (Figure 1). Thus, we assume that the functional role of TDAG51 may also be involved in the regulation of the unfolded protein response in the ER. Based on this hypothesis, it is possible to explain the enhancement of ROS levels in TDAG51-/- MEFs, although intensive studies are needed to reveal the mechanisms underlying a direct link between TDAG51 expression and ROS generation regulated by the unfolded protein response.
In conclusion, we investigated the role of TDAG51 in oxidative stress-induced apoptotic cell death during TDAG51 deficiency. TDAG51 expression was highly enhanced by oxidative stress responses. In response to oxidative stress, the production of intracellular ROS was significantly enhanced in TDAG51 $1^{-l}$ MEFs and resulted in the activation of caspase-3. Furthermore, TDAG51 deficiency enhanced apoptotic cell death in MEFs, and these results indicated that TDAG51 has a protective role in oxidative stress-induced cell death. Further studies will need to address the regulatory mechanism of the physiological significance of TDAG51 expression in the oxidative stress response.

\section{CONFLICT OF INTEREST}

The authors declare no conflict of interest.

\section{ACKNOWLEDGEMENTS}

This work was supported by the National Research Foundation of Korea Grant funded by the Korean Government (MSIP) (NRF-20110021771), Korea Basic Science Institute (D33400 and 2012-UniversityInsitute Cooperation Program) and the Ministry of National Defense Foundation Grant (ADD: 08-10-02).

1 Gogna R, Madan E, Kuppusamy P, Pati U. ROS-mediated p53 core-domain modifications determine apoptotic or necrotic death in cancer cells. Antioxid Redox Signal 2012; 16: 400-412.

2 Gorman AM, McGowan A, O'Neill C, Cotter T. Oxidative stress and apoptosis in neurodegeneration. J Neurol Sci 1996; 139: Suppl 45-52.

3 Tabas I, Ron D. Integrating the mechanisms of apoptosis induced by endoplasmic reticulum stress. Nat Cell Biol 2011; 13: 184-190.

4 Zhang K, Kaufman RJ. From endoplasmic-reticulum stress to the inflammatory response. Nature 2008; 454: 455-462.

5 Fulda S, Debatin KM. Extrinsic versus intrinsic apoptosis pathways in anticancer chemotherapy. Oncogene 2006; 25: 4798-4811.

6 Wajant $\mathrm{H}$. The Fas signaling pathway: more than a paradigm. Science 2002; 296: 1635-1636.

7 Kroemer G, Dallaporta B, Resche-Rigon M. The mitochondrial death/life regulator in apoptosis and necrosis. Annu Rev Physiol 1998; 60: 619-642.

8 Yoshida H, Kong YY, Yoshida R, Elia AJ, Hakem A, Hakem R et al. Apaf1 is required for mitochondrial pathways of apoptosis and brain development. Cell 1998; 94: 739-750.

9 Ray PD, Huang BW, Tsuji Y. Reactive oxygen species (ROS) homeostasis and redox regulation in cellular signaling. Cell Signal 2012; 24: 981-990.

10 Zhao L, Ackerman SL. Endoplasmic reticulum stress in health and disease. Curr Opin Cell Biol 2006; 18: 444-452.

11 Park CG, Lee SY, Kandala G, Choi Y. A novel gene product that couples TCR signaling to Fas(CD95) expression in activation-induced cell death. Immunity 1996; 4: 583-591.

12 Kuske MD, Johnson JP. Assignment of the human PHLDA1 gene to chromosome $12 \mathrm{q} 15$ by radiation hybrid mapping. Cytogenet Cell Genet 2000; 89: 1 .

13 Hayashida N, Inouye S, Fujimoto M, Tanaka Y, Izu H, Takaki E et al. A novel HSF1-mediated death pathway that is suppressed by heat shock proteins. EMBO J 2006; 25: 4773-4783.

14 Hossain GS, van Thienen JV, Werstuck GH, Zhou J, Sood SK, Dickhout JG et al. TDAG51 is induced by homocysteine, promotes detachmentmediated programmed cell death, and contributes to the cevelopment of atherosclerosis in hyperhomocysteinemia. J Biol Chem 2003; 278: 30317-30327.

15 Rho J, Gong S, Kim N, Choi Y. TDAG51 is not essential for Fas/CD95 regulation and apoptosis in vivo. Mol Cell Biol 2001; 21: 8365-8370.

16 Oberg HH, Sipos B, Kalthoff H, Janssen O, Kabelitz D. Regulation of T-cell death-associated gene 51 (TDAG51) expression in human T-cells. Cell Death Differ 2004; 11: 674-684. 
17 Muppidi J, Porter M, Siegel RM. Measurement of apoptosis and other forms of cell death. Curr Protoc Immunol 2004; Chapter 3: Unit3: 17.

18 Park ES, Choi S, Kim JM, Jeong Y, Choe J, Park CS et al. Early embryonic lethality caused by targeted disruption of the TRAF-interacting protein (TRIP) gene. Biochem Biophys Res Commun 2007; 363: 971-977.

19 Lu X, Kambe F, Cao X, Kozaki Y, Kaji T, Ishii T et al. 3beta-Hydroxysteroiddelta24 reductase is a hydrogen peroxide scavenger, protecting cells from oxidative stress-induced apoptosis. Endocrinology 2008; 149: 3267-3273.

20 Lee SH, Kim T, Park ES, Yang S, Jeong D, Choi Y et al. NHE10, an osteoclast-specific member of the $\mathrm{Na}+/ \mathrm{H}+$ exchanger family, regulates osteoclast differentiation and survival [corrected]. Biochem Biophys Res Commun 2008; 369: 320-326.

21 Yu J, Choi S, Park ES, Shin B, Lee SH, Takami M et al. D-chiro-inositol negatively regulates the formation of multinucleated osteoclasts by downregulating NFATc1. J Clin Immunol 2012; 32: 1360-1371.

22 Fedoroff N. Redox regulatory mechanisms in cellular stress responses. Ann Bot 2006; 98: 289-300.

23 Gomes I, Xiong W, Miki T, Rosner MR. A proline- and glutamine-rich protein promotes apoptosis in neuronal cells. J Neurochem 1999; 73: 612-622.

24 Lama G, Ferraraccio F, laccarino F, Luongo I, Marte A, Rambaldi PF et al. Pelviureteral junction obstruction: correlation of renal cell apoptosis and differential renal function. J Urol 2003; 169: 2335-2338.

25 Wang R, Zhang L, Yin D, Mufson RA, Shi Y. Protein kinase $C$ regulates Fas (CD95/APO-1) expression. J Immunol 1998; 161: 2201-2207.

26 Johnson EO, Chang KH, De Pablo Y, Ghosh S, Mehta R, Badve S et al. PHLDA1 is a crucial negative regulator and effector of Aurora A kinase in breast cancer. J Cell Sci 2011; 124 (Pt 16), 2711-2722.

27 Nagai MA, Fregnani JH, Netto MM, Brentani MM, Soares FA. Downregulation of PHLDA1 gene expression is associated with breast cancer progression. Breast Cancer Res Treat 2007; 106: 49-56.

28 Neef R, Kuske MA, Prols E, Johnson JP. Identification of the human PHLDA1/TDAG51 gene: down-regulation in metastatic melanoma contributes to apoptosis resistance and growth deregulation. Cancer Res 2002; 62: 5920-5929.

29 Toyoshima Y, Karas M, Yakar S, Dupont J, Lee H, LeRoith D. TDAG51 mediates the effects of insulin-like growth factor I (IGF-I) on cell survival. J Biol Chem 2004; 279: 25898-25904.

30 Sakthianandeswaren A, Christie M, D'Andreti C, Tsui C, Jorissen RN, Li S et al. PHLDA1 expression marks the putative epithelial stem cells and contributes to intestinal tumorigenesis. Cancer Res 2011; 71: 3709-3719.

31 Segditsas S, Sieber O, Deheragoda M, East P, Rowan A, Jeffery R et al. Putative direct and indirect Wnt targets identified through consistent gene expression changes in APC-mutant intestinal adenomas from humans and mice. Hum Mol Genet 2008; 17: 3864-3875.

32 Suzuki R, Miyamoto S, Yasui Y, Sugie S, Tanaka T. Global gene expression analysis of the mouse colonic mucosa treated with azoxymethane and dextran sodium sulfate. BMC Cancer 2007; 7: 84.

33 Bondia-Pons I, Ryan L, Martinez JA. Oxidative stress and inflammation interactions in human obesity. J Physiol Biochem68: 701-711.

34 Hirst J, King MS, Pryde KR. The production of reactive oxygen species by complex I. Biochem Soc Trans 2008; 36 (Pt 5), 976-980.

35 Boden G. Endoplasmic reticulum stress: another link between obesity and insulin resistance/inflammation? Diabetes 2009; 58: 518-519.

36 Ikesugi K, Yamamoto R, Mulhern ML, Shinohara T. Role of the unfolded protein response (UPR) in cataract formation. Exp Eye Res 2006; 83: 508-516.

37 Hinz T, Flindt S, Marx A, Janssen O, Kabelitz D. Inhibition of protein synthesis by the T cell receptor-inducible human TDAG51 gene product. Cell Signal 2001; 13: 345-352.

(1) () $\odot$ This work is licensed under a Creative Commons Attribution-NonCommercial-NoDerivs 3.0 Unported License. To view a copy of this license, visit http:// creativecommons.org/licenses/by-nc-nd/3.0/ 